Tropical Journal of Pharmaceutical Research November 2018; 17 (11): 2269-2274

ISSN: $1596-5996$ (print); 1596-9827 (electronic)

(C) Pharmacotherapy Group, Faculty of Pharmacy, University of Benin, Benin City, 300001 Nigeria.

\title{
Effect of CYP2C9 and VKORC1 genetic polymorphisms on warfarin dose requirement in Central China Han populations
}

\author{
Zhi-Jiang Li ${ }^{1}$, Xu Liü* \\ ${ }^{1}$ Department of Gallbladder Pancreas and Vascular Surgery, ${ }^{2}$ Department of Internal Medicine, Jingmen No. 1 People's \\ Hospital, Jingmen, Hubei, China
}

*For correspondence: Email: 3600109278@qq.com

Sent for review: 4 July 2018

Revised accepted: 25 October 2018

\begin{abstract}
Purpose: To investigate the frequency of CYP2C9 and vitamin $\mathrm{K}$ epoxide reductase complex subunit 1 (VKORC1) and determine the effect of these genetic factors on weekly warfarin dose requirement in Central China Han populations.

Methods: A total of 333 hospitalized patients with deep venous thrombosis after minimally invasive surgery were enrolled in this study. Genotypes of VKORC1 and CYP2C9 were analyzed by polymerase chain reaction (PCR)-DNA Chip method. Multiple linear regression analysis was used to explore the impact on weekly warfarin dose requirement.

Results: The allele frequencies of VKORC1 -1639 G and VKORC1 -1639 A were 0.105 and 0.895, respectively, whereas no genotype of CYP2C9*1*2, CYP2C9*2*2 and CYP2C9*3*3 were found, and the allele frequencies of CYP2C9*1, CYP2C9*2 and CYP2C9*3 were 0.943, 0.015 and 0.042, respectively. Multiple linear regression analysis indicated that several factors including VKORC1 -1639 G>A, CYP2C9*2, CYP2C9*3, age, body mass index (BMI) and amiodarone use may explain the $47.2 \%$ of individual variations in the weekly warfarin doses requirement.

Conclusion: There is no significant difference in the frequency of VKORC1 (-1639 G>A), CYP2C9*2 and CYP2C9*3 compared to those of Asian populations, but there is significant difference when compared with those of Europeans and Caucasians. Considering VKORC1-1639 G>A, CYP2C9*2, and CYP2C9*3 genetic polymorphisms as well as age, BMI and amiodarone use may explain the $47.2 \%$ of individual variations in the weekly warfarin doses requirement..
\end{abstract}

Keywords: Warfarin, CYP2C9, VKORC1, Polymorphism, Body mass index, International normalized ratio

This is an Open Access article that uses a funding model which does not charge readers or their institutions for access and distributed under the terms of the Creative Commons Attribution License (http://creativecommons.org/licenses/by/4.0) and the Budapest Open Access Initiative (http://www.budapestopenaccessinitiative.org/read), which permit unrestricted use, distribution, and reproduction in any medium, provided the original work is properly credited.

Tropical Journal of Pharmaceutical Research is indexed by Science Citation Index (SciSearch), Scopus, International Pharmaceutical Abstract, Chemical Abstracts, Embase, Index Copernicus, EBSCO, African Index Medicus, JournalSeek, Journal Citation Reports/Science Edition, Directory of Open Access Journals (DOAJ), African Journal Online, Bioline International, Open-J-Gate and Pharmacy Abstracts

\section{INTRODUCTION}

Warfarin, a vitamin $\mathrm{K}$ antagonist, is a highly effective and commonly oral anticoagulation therapy, but it has a narrow therapeutic index.
Under-anticoagulation or over-anticoagulation increased the risk of thrombosis and bleeding, respectively [1]. The international normalized ratio (INR) plays an important role in the efficacy and safety of warfarin treatment, thus, dosage 
adjustments are often necessary [2]. The variability in warfarin therapy is a multifactorial issue. Clinical and environmental variables, and genetic variation play important roles in the warfarin response [3]. The FDA requires manufacturers to revise the warfarin label based on genetic polymorphisms in vitamin $\mathrm{K}$ epoxide reductase subunit $\mathrm{C} 1$ (VKORC1) and CYP2C9 in January 2010 [4].

Warfarin is a racemic mixture including $S$ - and $\mathrm{R}$ enantiomers. The S-warfarin enantiomer is metabolized by CYP2C9, whereas R-warfarin enantiomer is metabolized by various CYPs, such as CYP1A1, CYP1A2, CYP3A4 [3]. Swarfarin plays a more important role than $\mathrm{R}$ warfarin [5]. CYP2C9*2 and CYP2C9*3 are common variants with reduced activity, and result in decrease warfarin doses requirement [6]. Both $\mathrm{R}$ - and S-warfarin inhibit the VKORC1 and prevent the activation of coagulation factors, thus exerting its anticoagulant effect [7]. VKORC1 ($1639 \mathrm{G}>\mathrm{A}$ ) reduces the expression of VKORC1, resulting in sensitivity to warfarin and resistance of warfarin [3].

CYP2C9 and VKORC1 mutations, as well as age and body mass index (BMI) can explain 40 63\% of individual variations in warfarin doses requirement [2]. However, genetic effects on warfarin dosing vary among different ethnic groups, live regions, lifestyle, culture, and dietary habits. Till date, no studies have been performed in the Central China Han population. The aim of this study was to determine the prevalence of allelic variants of VKORC1, CYP2C9 and their effect on warfarin dosage in Central China Han populations, providing a helpful clinical indicator for the safe dosage of warfarin.

\section{MATERIALS AND METHODS}

\section{Patients}

From December 2015 to October 2017, 333 patients were recruited from the Hospital of Hubei with deep venous thrombosis after the minimally invasive surgery, with an average age of 43 years. They were receiving stable weekly doses of warfarin, within a stable INR from 2 and 3.0 for at least 3 weeks. Mean weekly warfarin requirement was from 7 to $36 \mathrm{mg}$. Patients had no hepatic or renal diseases. Exclusion criteria included: hematological disease or hemorrhagic tendencies. The Ethics Committee of the Hospital of Hubei approved this study (approval no. 20151201). All participants signed an informed consent in compliance with the guidelines of Declaration of Helsinki [8].

\section{Data collection}

The medical variables were collected including gender, age, BMI, warfarin dose, INR values, alcohol drinking, and smoking status, medication history, concomitant diseases.

\section{Genotyping}

DNA was extracted with TIANamp Blood DNA Kit (Tiangen, China). The polymerase chain reaction (PCR)- DNA Chip method was used to determine the polymorphisms in VKORC1 (rs9923231) and CYP2C9*2 (rs1799853) and CYP2C9*3 (rs1057910). Sanger sequencing was used to confirm the above results.

\section{Statistical analysis}

Data was performed using SPSS 19.0 (SPSS, Inc, Chicago, IL, USA). Continuous variables were presented as means \pm standard deviation (SD), and analyzed using independent-samples t-test, or ANOVA. Categorical variables were expressed as frequencies and percentages, and analyzed using Chi-square analyses. $\mathrm{P}<0.05$ was accepted as statistically significant.

\section{RESULTS}

\section{Clinical characteristics}

A total of 333 patients with deep venous thrombosis were enrolled to this study, including 137 males (41.14\%) and 196 females (58.86\%), the age ranged from 21 to 78 years (a mean age of $43.26 \pm 12.56$ years). Average body mass index (BMI) of the 333 patients was $24.68 \pm 4.69 \mathrm{~kg} / \mathrm{m}^{2}$. Average warfarin maintenance dose ranged from 7 to $36 \mathrm{mg} /$ week. Body surface area (BSA) of patients ranged from 1.26 to $2.43 \mathrm{~m}^{2}$, with a mean of $1.65 \pm 0.85 \mathrm{~m}^{2}$. 333 patients had controlled their INR values ranged from 1.5 to 3.0. Patient characteristics are summarized in Table 1.

Table 1: Patient characteristics

\begin{tabular}{lc}
\hline Variable & $\begin{array}{c}\text { Patients } \\
(\mathbf{n}=333)\end{array}$ \\
\hline Age (mean $\pm S D$, years) & $43.26 \pm 12.56$ \\
Gender (female, $\mathrm{n}, \%)$ & $196(58.86)$ \\
$\mathrm{BMI}\left(\mathrm{kg} / \mathrm{m}^{2}\right)$ & $24.68 \pm 4.69$ \\
$\mathrm{BSA}\left(\mathrm{m}^{2}\right)$ & $1.65 \pm 0.85$ \\
Smoking $(\mathrm{n}, \%)$ & $84(25.23)$ \\
Drinking $(\mathrm{n}, \%)$ & $41(12.31)$ \\
Amiodarone use $(\mathrm{n}, \%)$ & $25(7.51)$ \\
Enzyme inducers $(\mathrm{n}, \%)$ & $11(3.30)$ \\
INR & $2.35 \pm 0.78$ \\
Maintenance dose $(\mathrm{mg} /$ week $)$ & $20.65 \pm 12.26$ \\
\hline
\end{tabular}




\section{Genotype, allele frequencies and ethnicity}

Genotype frequencies did not reveal deviations from Hardy-Weinberg equilibrium. For the VKORC1 gene, frequencies of genotype GG, AG and AA were $0.015,0.180$ and 0.805 , respectively, and allele frequencies of $G$ and $A$ were 0.105 and 0.895 , respectively, the frequency of allele $\mathrm{G}$ was significantly lower than Caucasian, English, French, Brazil, Chinese Uygur and Greek, and similar to Thai, Taiwan and West China (Table 2).

For the CYP2C9 gene, frequencies of genotype, ${ }^{*} 1{ }^{*} 1,{ }^{*} 1{ }^{*} 2,{ }^{*} 1{ }^{*} 3{ }^{*}{ }^{*} 2,{ }^{*} 2{ }^{*} 3$ and ${ }^{*} 3{ }^{*} 3$ were 0.916 , $0,0,0.069,0.015$ and 0 , respectively, and the allele frequencies of ${ }^{*} 1,{ }^{*} 2$ and ${ }^{*} 3$ were 0.943 , 0.015 and 0.042 , respectively, which were significantly different among Khorasan, Gorgan, Tunisian, Caucasian and Egyptian, and similar to Japanese and Korean (Table 3).

\section{Impact of VKORC1 -1639 G/A, CYP2C9*2 and CYP2C9*3 SNPs on the weekly stable warfarin dose}

The association of the mean weekly warfarin dosage in patients with various genotype is shown in Table 4 and Figure 1. The mean weekly warfarin dosage in patients with VKORC1 GA genotype was significantly higher than those of AA genotype $(28.2 \pm 8.5$ vs $18.9 \pm 6.8 \mathrm{mg} /$ weekly; $P<0.001$ ), while the wild type carrier of VKORC1 -1639 GG required a much higher dose than the GA or AA carriers $(38.6 \pm 7.7$ vs $28.2 \pm 8.5$ $\mathrm{mg} /$ weekly, $38.6 \pm 7.7$ vs $18.9 \pm 6.8 \mathrm{mg} /$ weekly, respectively, all $P<0.001$ ). The mean weekly warfarin dosage in patients with CYP2C9*1/*3 genotype was significantly higher than those of ${ }^{*} 2 /{ }^{*} 3$ genotype $(15.1 \pm 4.9$ vs $9.1 \pm 3.2 \mathrm{mg} /$ weekly; $P<0.001$ ), while the wild type carrier required a much higher dose than the CYP2C9*1/*3 or CYP2C $9{ }^{*} 2 /{ }^{*} 3$ carriers $(23.2 \pm 8.6$ vs $15.1 \pm 4.9$ $\mathrm{mg} /$ weekly, $23.2 \pm 8.6$ vs $9.1 \pm 3.2 \mathrm{mg} /$ weekly, respectively, all $P<0.001$ ).

\section{Contribution of demographic characteristics and genotype variation to the weekly stable warfarin dose}

Multiple linear regression analysis for variables (demographic characteristics and genotype) responsible for the weekly stable warfarin doses. Our data indicated that several factors including VKORC1 -1639 G/A, CYP2C9*2, CYP2C9*3, age, BMI and amiodarone use could explain $47.2 \%$ of individual variations in warfarin doses

Table 2: Genotype distributions and allele frequencies of VKORC1 -1639 G/A in different races

\begin{tabular}{lccccc}
\hline \multirow{2}{*}{ Race } & \multicolumn{3}{c}{$\begin{array}{c}\text { VKORC1-1639 G/A } \\
\text { Genotype }\end{array}$} & \multicolumn{2}{c}{$\begin{array}{c}\text { VKORC1-1639 G/A } \\
\text { Alle frequency }\end{array}$} \\
\cline { 2 - 6 } & GG & AG & AA & G & A \\
\hline Caucasian population [9] & 0.39 & 0.47 & 0.14 & 0.72 & 0.38 \\
English population [10] & 0.19 & 0.56 & 0.25 & 0.53 & 0.47 \\
French population [11] & 0.22 & 0.35 & 0.43 & 0.58 & 0.42 \\
Brazil population [12] & 0.495 & 0.411 & 0.094 & 0.70 & 0.30 \\
Thai [13] & 0.028 & 0.280 & 0.692 & 0.168 & 0.832 \\
Chinese Uygur population [8] & 0.09 & 0.58 & 0.33 & 0.38 & 0.62 \\
Taiwan Han population [9] & 0.00 & 0.18 & 0.82 & 0.09 & 0.91 \\
West China Han populations [14] & 0.004 & 0.19 & 0.80 & 0.10 & 0.90 \\
Greek-Cypriot population [15] & 0.230 & 0.473 & 0.297 & 0.466 & 0.534 \\
Present study & 0.015 & 0.180 & 0.805 & 0.105 & 0.895 \\
\hline
\end{tabular}

Table 3: Distribution of genotype frequencies of CYP2C9*2 and CYP2C9*3 in different races

\begin{tabular}{|c|c|c|c|c|c|c|}
\hline \multirow{2}{*}{ Race } & \multicolumn{6}{|c|}{ CYP2C9 genotype frequency } \\
\hline & ${ }^{*}{ }^{*} 1$ & ${ }^{*} 1{ }^{\star} 2$ & ${ }^{\star} 2 \star 2$ & ${ }^{*} 1 * 3$ & ${ }^{\star} 2 * 3$ & *3*3 \\
\hline Southern Khorasan population [16] & 0.641 & 0.158 & 0 & 0.175 & 0.025 & 0 \\
\hline Sistani Ethnic Group in Gorgan [17] & 0.539 & 0.221 & 0.029 & 0.114 & 0.043 & 0 \\
\hline Uruguayan Caucasian population [18] & 0.68 & 0.22 & 0.02 & 0.08 & 0 & 0 \\
\hline Bangladeshi population [19] & 0.92 & 0 & 0 & 0.046 & 0 & 0.034 \\
\hline Iranian Baluch Ethnic Group [20] & 0.709 & 0.118 & 0.455 & 0.818 & 0.273 & 0.182 \\
\hline Ghanaian population [3] & 1.00 & 0 & 0 & 0 & 0 & 0 \\
\hline Tunisian population [21] & 0.616 & 0.194 & 0.027 & 0.132 & 0.031 & 0 \\
\hline Japanese [22] & 0.87 & 0 & 0 & 0.13 & 0 & 0 \\
\hline Korean [22] & 0.86 & 0 & 0 & 0.14 & 0 & 0 \\
\hline Caucasian [22] & 0.67 & 0.17 & 0.03 & 0.13 & 0 & 0 \\
\hline Egyptian population [23] & 0.664 & 0.19 & 0.024 & 0.117 & 0 & 0.04 \\
\hline Present study & 0.916 & 0 & 0 & 0.069 & 0.015 & 0 \\
\hline
\end{tabular}


Table 4: Weekly doses of warfarin in patients with various genotypes

\begin{tabular}{lll}
\hline Genotype & Number (\%) & $\begin{array}{l}\text { Weekly doses (mg, } \\
\text { mean } \pm \text { SD) }\end{array}$ \\
\hline $\begin{array}{l}\text { VKORC1 -1639 G/A } \\
\text { Genotype }\end{array}$ & \\
GG & $5(1.5)$ & $38.6 \pm 7.7$ \\
GA & $60(18.5)$ & $28.2 \pm 8.5$ \\
AA & $268(80.0)$ & $18.9 \pm 6.8$ \\
CYP2C9 & & \\
Genotype & & \\
${ }^{*} 1 /{ }^{*}$ & $305(91.6)$ & $23.2 \pm 8.6$ \\
${ }^{*} 1 /{ }^{*} 2$ & $0(0)$ & - \\
${ }^{*} 1 /{ }^{*} 3$ & $23(6.9)$ & - \\
${ }^{*} 2 /{ }^{*} 2$ & $0(0)$ & $-15.1 \pm 4.9$ \\
${ }^{*} 3 /{ }^{*} 3$ & $5(1.5)$ & - \\
\hline
\end{tabular}

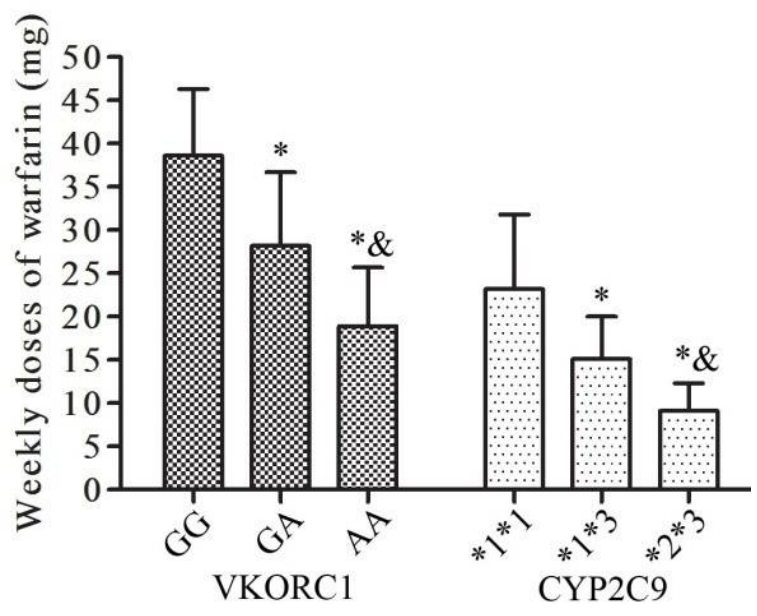

Figure 1: Weekly doses of warfarin (mean $\pm \mathrm{SD}, \mathrm{mg}$ ) in patients with various genotypes. The differences in warfarin dose between the various genotypes were analyzed by one-way ANOVA; for VKORC1, compared with GG, ${ }^{*} p<0.001$, compared with $\mathrm{GA},{ }^{\&} p$ $<0.001$; for CYP2C9, compared with *1*1, ${ }^{*} p<0.001$, compared with * $1 * 3,{ }^{*} p<0.001$

Table 5: Demographic and genetic variables responsible for stable weekly warfarin dose by multiple linear regression
G/A contributed the most $(25.2 \%)$ to individual variations in warfarin doses requirement.

\section{DISCUSSION}

VKORC1 and CYP2C9 genetic polymorphisms, age, BMI and concomitant drugs affect warfarin stable dose requirements, however, about $50 \%$ of warfarin dose variation remaining unexplained [24]. Most studies mainly focused on the warfarin stable dose, but neglected the initial response to warfarin therapy, patients with over- or underanticoagulation increase the risk of bleeding or thrombosis. 333 Central Chinese patients undergoing warfarin therapy participated in our present study, we monitored a wider range of outcomes of the patients from initiation to a 6month follow-up. Our data indicated that several factors including VKORC1 -1639 G/A, CYP2C9*2, CYP2C9*3, age, BMI and amiodarone use could explain $47.2 \%$ of individual variations in the weekly stable warfarin doses. Our study is the first to assess impact of genetic polymorphisms of CYP2C9, VKORC1, enzyme inhibitor (amiodarone) and BMI on warfarin dose requirements in Central China Han populations.

\begin{tabular}{|c|c|c|c|}
\hline$\overline{\text { Variable }}$ & $\begin{array}{c}\text { Standardized } \\
\text { coefficient }\end{array}$ & $\begin{array}{c}\text { Contribution } \\
(\%)\end{array}$ & $P$-value \\
\hline Age & -0.162 & 8.6 & $<0.001$ \\
\hline BMI & 0.035 & 2.6 & $<0.001$ \\
\hline $\begin{array}{l}\text { VKORC1 (- } \\
1639 \mathrm{G} / \mathrm{A})\end{array}$ & -16.529 & 25.2 & $<0.001$ \\
\hline CYP2C9*2 & -9.582 & 2.2 & $<0.001$ \\
\hline CYP2C9*3 & -12.85 & 5.1 & $<0.001$ \\
\hline $\begin{array}{l}\text { Amiodarone } \\
\text { use }\end{array}$ & -6.905 & 3.5 & $<0.001$ \\
\hline
\end{tabular}

requirement (Table 5). Age, amiodarone use, genotypes of VKORC1 -1639 G>A, CYP2C9*2, CYP2C9*3 were negatively associated with weekly stable warfarin doses; VKORC1 -1639
Our study showed that the frequencies of allele $G$ and $A$ of VKORC1 gene were 0.105 and 0.895 , respectively, and the allele frequencies of ${ }^{*} 1,{ }^{*} 2$ and ${ }^{*} 3$ of CYP2C9 were $0.943,0.015$ and 0.042 , respectively. The allele frequencies of $G$ of VKORC1, CYP2C9*2 and CYP2C9*3 were significantly different among European and Caucasian populations, but similar to Asian populations (Table 2 and Table 3). Furthermore, the weekly warfarin doses requirement of patients with VKORC1, CYP2C9 wild type were significantly higher than those of with the mutant types $(p<0.001)$. 
In this present study, we found that VKORC1 ($1639 \mathrm{G}>\mathrm{A}$ ), CYP2C9 ${ }^{*} 2$ and ${ }^{*} 3$ are the major genetic factors of warfarin dose which confirmed the previous findings [9]. Bourgeois et al found that beyond VKORC1 and $\mathrm{CYP} 2 \mathrm{C}$, other genetic factors are unlikely associated with the variance in warfarin dose [24]. Our study found that VKORC1 -1639 G/A could explain $25.2 \%$ of individual variations in the weekly stable warfarin doses which also confirmed the previous studies, and the VKORC1 -1639 G/A polymorphism contributed the most to individual variance [24].

In this present study, the contribution of VKORC1 $(25.2 \%)$ was greater than those of CYP2C9 (7.3 $\%$, which confirmed the previous findings [13]. Until now, some previous studies reported that the contribution of $\mathrm{CYP} 2 \mathrm{C9}^{*} 3$ ranged from $1.7 \sim 6.0 \%$ in Asians [13], however, the CYP2C9*3 explained $5.1 \%$ of the weekly stable warfarin dose variance in our study, which was lower than Caucasian populations (12.9\%) [24]. In Asians, CYP2C9*2 mutation is rare and CYP2C9*3 mutation frequency is relatively lower [25], therefore, the CYP2C9*3 allele accounted for a lower proportion compared with Caucasians.

In the present study, we found that non-genetics factors including age, BMI and amiodarone use explained $14.7 \%$ of individual variations in the weekly warfarin doses requirement, which were similar to the results previously reported [13]. Compared with genetic factors, the contribution of non-genetics factors to explain the warfarin dose variance is lower. In non-genetic factors, age accounted for the largest proportion (8.6\%) to the weekly warfarin doses variance, which was similar to previous report [13]. In addition, BMI and amiodarone explained $2.6 \%$ and $3.5 \%$ of the dose variance, respectively. Therefore, this results may help the clinicians in considering VKORC1 -1639 G >A, CYP2C9*2, and CYP2C9*3 genetic polymorphisms as well as age, BMI and amiodarone use for individual variations in the weekly warfarin doses requirement, and reduce the rate of complications.

\section{CONCLUSION}

There is no significant difference in the frequency of VKORC1 (-1639 G>A), CYP2C9*2 and CYP2C9*3 compared to those of Asian populations, but there is significant difference when compared with those of Europeans and Caucasians. Considering VKORC1 -1639 G>A, CYP2C9*2, and CYP2C9*3 genetic polymorphisms and age, BMI and amiodarone use may explain the $47.2 \%$ of individual variations in the weekly warfarin doses requirement.

\section{DECLARATIONS}

\section{Acknowledgement}

The authors thank all the volunteers who participated in this study.

\section{Conflict of interest}

No conflict of interest is associated with this study.

\section{Contribution of authors}

We declare that this work was done by the authors named in this article and all liabilities pertaining to claims relating to the content of this article will be borne by the authors. Conceived and designed the experiments: Zhi-Jiang $\mathrm{Li}$ and Xu Liu. Performed the experiments: Zhi-Jiang Li and Xu Liu. Analyzed the data: Xu Liu. Wrote the paper: Zhi-Jiang Li and Xu Liu.

\section{REFERENCES}

1. Iwuchukwu OF, Ramirez AH, Shi Y, Bowton EA, Kawai VK, Schildcrout JS, Roden DM, Denny JC, Stein CM. Genetic Determinants of Variability in Warfarin Response after the Dose-Titration Phase. Pharmacogenet Genomics 2016; 26: 510-516.

2. Valentin, li, Vazquez J, Rivera-Miranda G, Seip RL, Velez M, Kocherla M, Bogaard K, Cruz-Gonzalez I, Cadilla CL, Renta JY, et al. Prediction of Warfarin Dose Reductions in Puerto Rican Patients, Based on Combinatorial Cyp2c9 and Vkorc1 Genotypes. Ann Pharmacother 2012; 46: 208-218.

3. Kudzi W, Ahorhorlu SY, Dzudzor B, Olayemi E, Nartey ET, Asmah RH. Genetic Polymorphisms of Patients on Stable Warfarin Maintenance Therapy in a Ghanaian Population. BMC Res Notes 2016; 9: 507.

4. Finkelman BS, Gage BF, Johnson JA, Brensinger CM, Kimmel SE. Genetic Warfarin Dosing: Tables Versus Algorithms. J Am Coll Cardiol 2011; 57: 612-618.

5. Yildirim E, Erol K, Birdane A. Warfarin Dose Requirement in Turkish Patients: The Influences of Patient Characteristics and Polymorphisms in Cyp2c9, Vkorc1 and Factor Vii. Hippokratia 2014; 18: 319-327.

6. Gage BF, Eby C, Milligan PE, Banet GA, Duncan JR, Mcleod HL. Use of Pharmacogenetics and Clinical Factors to Predict the Maintenance Dose of Warfarin. Thromb Haemost 2004; 91: 87-94.

7. Suarez-Kurtz G, Botton MR. Pharmacogenomics of Warfarin in Populations of African Descent. Br J Clin Pharmacol 2013; 75: 334-346.

8. Yan X, Yang F, Zhou H, Zhang H, Liu J, Ma K, Li Y, Zhu $J$, Ding J. Effects of Vkorc1 Genetic Polymorphisms on

Trop J Pharm Res, November 2018; 17(11): 2273 
Warfarin Maintenance Dose Requirement in a Chinese Han Population. Med Sci Monit 2015; 21: 3577-3584.

9. Yuan HY, Chen JJ, Lee MT, Wung JC, Chen YF, Charng MJ, Lu MJ, Hung CR, Wei CY, Chen $\mathrm{CH}$, et al. A Novel Functional Vkorc1 Promoter Polymorphism is Associated with Inter-Individual and Inter-Ethnic Differences in Warfarin Sensitivity. Hum Mol Genet 2005; 14: 1745-1751.

10. Sconce EA, Khan TI, Wynne HA, Avery P, Monkhouse L, King BP, Wood P, Kesteven P, Daly AK, Kamali F. The Impact of Cyp2c9 and Vkorc1 Genetic Polymorphism and Patient Characteristics Upon Warfarin Dose Requirements: Proposal for a New Dosing Regimen. Blood 2005; 106: 2329-2333.

11. Bodin $L$, Verstuyft $C$, Tregouet $D A$, Robert A, Dubert $L$, Funck-Brentano $C$, Jaillon $P$, Beaune $P$, Laurent-Puig $P$, Becquemont L, et al. Cytochrome P450 2c9 (Cyp2c9) and Vitamin K Epoxide Reductase (Vkorc1) Genotypes as Determinants of Acenocoumarol Sensitivity. Blood 2005; 106: 135-140.

12. Tavares LC, Marcatto LR, Soares RaG, Krieger JE, Pereira AC, Santos P. Association between Abcb1 Polymorphism and Stable Warfarin Dose Requirements in Brazilian Patients. Front Pharmacol 2018; 9: 542.

13. Wattanachai N, Kaewmoongkun S, Pussadhamma B, Makarawate $P$, Wongvipaporn $C$, Kiatchoosakun $S$, Vannaprasaht S, Tassaneeyakul W. The Impact of NonGenetic and Genetic Factors on a Stable Warfarin Dose in Thai Patients. Eur J Clin Pharmacol 2017; 73: 973980.

14. Li J, Yang W, Xie Z, Yu K, Chen Y, Cui K. Impact of Vkorc1, Cyp4f2 and Nqo1 Gene Variants on Warfarin Dose Requirement in Han Chinese Patients with Catheter Ablation for Atrial Fibrillation. BMC Cardiovasc Disord 2018; 18: 96.

15. Hadjipanagi D, Chrysanthou S, Voskarides K, Deltas C. Genetic Polymorphisms in Warfarin and TacrolimusRelated Genes Vkorc1, Cyp2c9 and Cyp3a5 in the Greek-Cypriot Population. BMC Res Notes 2014; 7: 123.

16. Razavi FE, Zarban A, Hajipoor F, Naseri M. The Allele Frequency of Cyp2c9 and Vkorc1 in the Southern Khorasan Population. Res Pharm Sci 2017; 12: 211 221.
17. Marjani A, Gharanjik AM. Genetic Polymorphism of Cyp2c9 among Sistani Ethnic Group in Gorgan. Indian J Clin Biochem 2018; 33: 208-213.

18. Guevara N, Maldonado C, Uria M, Gonzalez R, Ibarra M, Alvariza S, Carozzi A, Azambuja C, Fagiolino $P$, Vazquez M. Role of Cyp2c9, Cyp2c19 and Ephx Polymorphism in the Pharmacokinetic of Phenytoin: $A$ Study on Uruguayan Caucasian Subjects. Pharmaceuticals (Basel) 2017; 10.

19. Chowdhury ZS, Shahjin F, Akter F, Ahmed M, Islam MS, Bin Sayeed MS, Islam R, Hasnat A. Effect of Vkorc1 and Cyp2c9 Polymorphisms on Warfarin Dose Requirement in Bangladeshi Population. Pak J Pharm Sci 2017; 30: 341-346.

20. Tabari MG, Naseri F, Ataby MA, Marjani A. Genetic Polymorphism of Cytochrome P450 (2c9) Enzyme in Iranian Baluch Ethnic Group. Open Biochem J 2015; 9: 37-41.

21. Abdelhedi R, Bouayed NA, Alfadhli S, Abid L, Rebai A, Kharrat N. Characterization of Drug-Metabolizing Enzymes Cyp2c9, Cyp2c19 Polymorphisms in Tunisian, Kuwaiti and Bahraini Populations. J Genet 2015; 94: 765-770.

22. Hasunuma T, Tohkin M, Kaniwa $N$, Jang IJ, Yimin $C$, Kaneko M, Saito Y, Takeuchi M, Watanabe H, Yamazoe $Y$, et al. Absence of Ethnic Differences in the Pharmacokinetics of Moxifloxacin, Simvastatin, and Meloxicam among Three East Asian Populations and Caucasians. Br J Clin Pharmacol 2016; 81: 1078-1090.

23. Hamdy SI, Hiratsuka M, Narahara K, El-Enany M, Moursi N, Ahmed MS, Mizugaki M. Allele and Genotype Frequencies of Polymorphic Cytochromes P450 (Cyp2c9, Cyp2c19, Cyp2e1) and Dihydropyrimidine Dehydrogenase (Dpyd) in the Egyptian Population. Br J Clin Pharmacol 2002; 53: 596-603.

24. Bourgeois $S$, Jorgensen A, Zhang EJ, Hanson A, Gillman MS, Bumpstead S, Toh CH, Williamson P, Daly AK, Kamali $F$, et al. A Multi-Factorial Analysis of Response to Warfarin in a Uk Prospective Cohort. Genome Med 2016; 8: 2.

25. Xie HG, Prasad HC, Kim RB, Stein CM. Cyp2c9 Allelic Variants: Ethnic Distribution and Functional Significance. Adv Drug Deliv Rev 2002; 54: 1257-1270. 